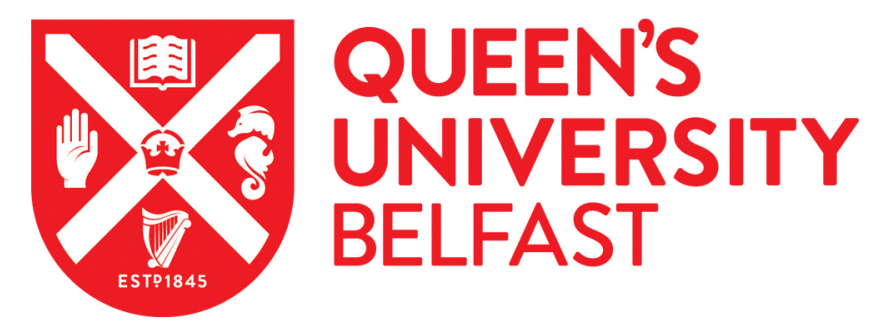

\title{
The effect of the linker size in C2-symmetrical chiral ligands on the self-assembly formation of luminescent triple-stranded di-metallic $\mathrm{Eu}(\mathrm{III})$ helicates in solution
}

Kotova, O., Comby, S., Pandurangan, K., Stomeo, F., O'Brien, J. E., Feeney, M., Peacock, R. D., McCoy, C. P., \& Gunnlaugsson, T. (2018). The effect of the linker size in C2-symmetrical chiral ligands on the self-assembly formation of luminescent triple-stranded di-metallic Eu(III) helicates in solution. Dalton Transactions, 47(35), 12308-12317. https://doi.org/10.1039/c8dt02753f

Published in:

Dalton Transactions

Document Version:

Peer reviewed version

Queen's University Belfast - Research Portal:

Link to publication record in Queen's University Belfast Research Portal

\section{Publisher rights}

(c) 2018 The Royal Society of Chemistry. This work is made available online in accordance with the publisher's policies. Please refer to any applicable terms of use of the publisher.

\section{General rights}

Copyright for the publications made accessible via the Queen's University Belfast Research Portal is retained by the author(s) and / or other copyright owners and it is a condition of accessing these publications that users recognise and abide by the legal requirements associated with these rights.

Take down policy

The Research Portal is Queen's institutional repository that provides access to Queen's research output. Every effort has been made to ensure that content in the Research Portal does not infringe any person's rights, or applicable UK laws. If you discover content in the

Research Portal that you believe breaches copyright or violates any law, please contact openaccess@qub.ac.uk. 


\title{
The effect of the linker size in C2-symmetrical chiral ligands on the self- assembly formation of luminescent triple-stranded di-metallic Eu(III)
}

\section{helicates in solution $\uparrow$}

Oxana Kotova ${ }^{*}$, Steve Comby ${ }^{\mathrm{a}}$, Komala Pandurangan ${ }^{\mathrm{a}}$, Floriana Stomeo ${ }^{\mathrm{a}}$, John E. O’Brien ${ }^{\mathrm{a}}$, Martin Feeney ${ }^{\mathrm{a}}$, Robert D. Peacock ${ }^{\mathrm{b}}$, Colin P. McCoy ${ }^{\mathrm{c}}$ and Thorfinnur Gunnlaugsson ${ }^{{ }^{\mathrm{a}}}$

aSchool of Chemistry, Trinity Biomedical Sciences Institute (TBSI),

Trinity College Dublin, Dublin 2, Ireland.

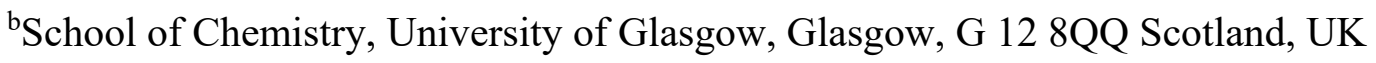

'School of Pharmacy, Queen's University Belfast, 97 Lisburn Road, Belfast, BT9 7BL

Northern Ireland, UK

E-mail:kotovao@tcd.ie, gunnlaut@tcd.ie

\begin{abstract}
Chiral lanthanide-based supramolecular structures have gained significant importance in view of their application in imaging, sensing and other functional purposes. We have designed chiral C2-symmetrical ligands (L) based on the use of two 2,6-pyridine-dicarboxylic-amide moieties (pda), that differ from one another by the nature of the diamine spacer groups (from 1,3-phenylenedimethanamine (1(S,S), 2(R,R)) and benzene-1,3-diamine (3(S,S), 4(R,R)) to much bulkier 4,4'-(cyclohexane-1,1-diyl)bis(2,6-dimethyl- aniline) $(5(\mathrm{~S}, \mathrm{~S}), 6(\mathrm{R}, \mathrm{R})))$ between these two pda units. The self-assembly between L and Eu(III) ions were investigated in $\mathrm{CH} 3 \mathrm{CN}$ solution at low concentration whereby the changes in the absorbance, fluorescence and $\mathrm{Eu}(\mathrm{III})$-centred emission spectra allowed us to model the binding equilibria occurring in
\end{abstract}


the solution to the presence of [Eu:L2], [Eu2:L2], [Eu2:L3] assemblies and reveal their high binding constant values. The self-assembly in solution were also studied at higher concentration by following the changes in the $1 \mathrm{H}$ NMR spectra of the ligands upon $\mathrm{Eu}(\mathrm{III})$ addition, as well as by using MALDI-MS of the isolated solid state complexes. The chiroptical properties of the ligands were used in order to study the structural changes upon self-assembly between the ligands and Eu(III) ions using circular dichroism (CD) and circularly polarised luminescence (CPL) spectroscopies. The photophysical properties of [Eu2:L3] complexes were evaluated in solution and showed a decrease of luminescence quantum yield when going from the ligand with smaller $(1(\mathrm{~S}, \mathrm{~S}))$ to bulkier $(5(\mathrm{~S}, \mathrm{~S}))$ linker from $\sim 5.8 \%$ to $\sim 2.6 \%$. While mass-spectrometry revealed the possible formation of trinucler assemblies such as [Eu3:L3] and [Eu3:L2].

\section{Introduction}

The design of self-assembled lanthanide ( $\mathrm{Ln})$ complexes with triple-stranded di-metallic helical motif is inspired by the architecture, mechanics and structural features of biological macromolecules and driven by the possible application of such systems thanks to the unique magnetic and spectroscopic properties of the metal centres. 1 The first di-metallic lanthanide helicates were reported by Piguet et al.2 and since then, the structural and thermodynamic parameters of such systems were investigated 3 moving towards nd- $4 \mathrm{f}$ helicates, 4 polymeric helical structures, 5 and water soluble systems for imaging applications.6 Such systems were also developed as sensors for adenosine monophosphate, fluoride7 and chiral helical structures; which we also investigate within our research group. 8 The design of the ligands is crucial in order to achieve lanthanide complexes with triple-stranded di-metallic helical motif and modifications of ligand design have been recently proven successful in moving from triple stranded helicates towards achieving 3D helical structures, 9 pentanuclear lanthanide 
heli- cates, 10 tetranuclear tetrahedrons and octanuclear cubes, 11 or cages.12 Recently, another interesting approach has been shown where one can move from the use of dinuclear bis- $\beta$-diketonate lanthanide complexes, 13 to D2-symmetrical alter- nating circular helicate, by simply combining achiral bis- $\beta$-diketonate and chiral Pybox ligands within a single ligand structure.14 In our research group, we have based our ligand design on connecting two chiral half-helicate ligands either (S) or (R) 6-(1-(naphthalen-1-yl)ethylcarbamoyl)picolinic acid with diamine spacers such as 4,4'-methylenedianiline,8a 3,3'-methyl-enedianiline $8 \mathrm{~b}$ or smaller 1,3-phenylenedi-methanamine.8c The interaction of these ligands with lanthanide ions in solution resulted in the formation of enantiomerically pure luminescent triple-stranded di-metallic Ln(III) helicates. The use of 2,6-pyridinedicarboxamide (pda) binding unit is very appealing for the formation of various types of $\mathrm{Ln}(\mathrm{III})$ bun- dles8g including highly novel systems such as molecular trefoil knots, 15a,b elegantly developed by Leigh and co-workers, that can be used in asymmetric catalysis.15c This concept was recently expanded for $\mathrm{Zn}$ (II) systems where trefoil knots were formed from trimeric circular helicates, $15 \mathrm{~d}$ and by securing a supramolecular architecture by tying a stopper in mechanically interlocked molecules. $15 \mathrm{e}$ In this work we continue our helicate endeavour with $\mathrm{Eu}(\mathrm{III})$ and investigate the effect of the spacer size on the formation of lanthanide self-assembly structures in solution by comparing the system published earlier (ligands 1-2)8c with the new ligands where shorter benzene-1,3diamine (ligands 3-4, Scheme 1) or much bulkier spacer such as 4,4'-(cyclohexane- 1,1diyl)bis(2,6-dimethylaniline) (ligands 5-6) were utilised (Scheme 1).

The structural changes of the ligand upon self-assembly with $\mathrm{Eu}(\mathrm{III})$ in solution were accessed with the aid of spectroscopic techniques by monitoring the changes in the absorbance, fluorescence and Eu(III)-centred emission of the ligand upon metal addition at low concentration, as well as circular dichroism (CD) and circularly polarised luminescence (CPL) spectroscopies, in addition to 1H NMR spectroscopy at higher ligand concentrations. 

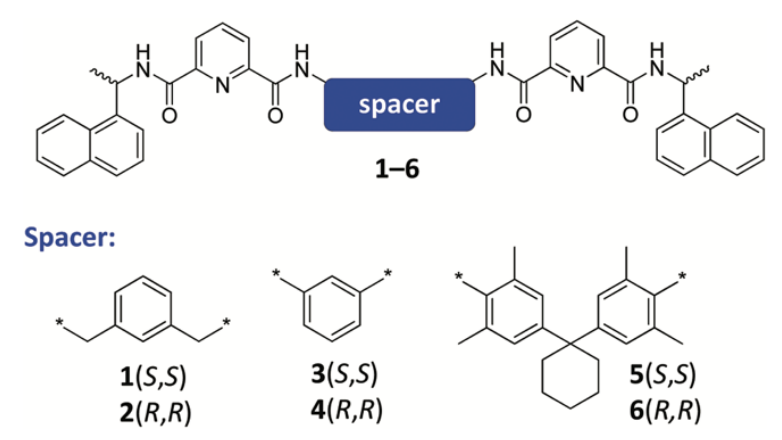

Scheme 1

Structural formulas of the ligands $1-6$.

\section{Results and discussion}

\section{Synthesis of ligands $1-6$}

The ligands were synthesised in four steps (Scheme S1, ESI $\dagger$ ) starting from 2,6-pyridinedicarboxylic acid through protecting one of the carboxylic acids by reacting it with benzyl bromide. The remaining carboxylic acid group, of resulting compound 16 (see ESI, Scheme $\mathrm{S} 1 \dagger)$ was coupled with (S) or (R) 1-(naphthalen-1-yl)ethanamine using N-(3-dimethylaminopropyl)-N'-ethylcarbodiimide (EDCI), 1-hydroxybenzo- triazole (HOBt) as coupling reagents in dichloromethane resulting in the formation of compounds 12, 13 (Scheme S1, ESI $\dagger$ ), followed by de-protection using hydrogenation in the presence of or $\mathrm{Pd} / \mathrm{C}$ as a catalyst. These so-called "half-helicate" compounds (either 10 or 11, Scheme S1, ESI†) were then coupled with the desired "spacer" diamines (Scheme 1) using the same peptide coupling reagents as before, in the presence of trimethylamine and 4-dimethylaminopyridine as catalyst. It has to be noted that 1,3-phenylenediamine linker (8) was obtained from commercial sources while 4,4'-(cyclohexane-1,1- diyl)bis(2,6-dimethylaniline) linker (9) was synthesised following the procedures reported previously by Hunter et al.17 Ligands 3-6 (Scheme 1) were obtained in $\sim 20-25 \%$ yield and their com- position was confirmed by a 
combination of $1 \mathrm{H}, 13 \mathrm{C}$ and heteronuclear single quantum correlation (HSQC) NMR experiments along with electrospray mass-spectrometry (ESI-MS), IR and elemental analysis (see ESI, Fig. S1-S14†).
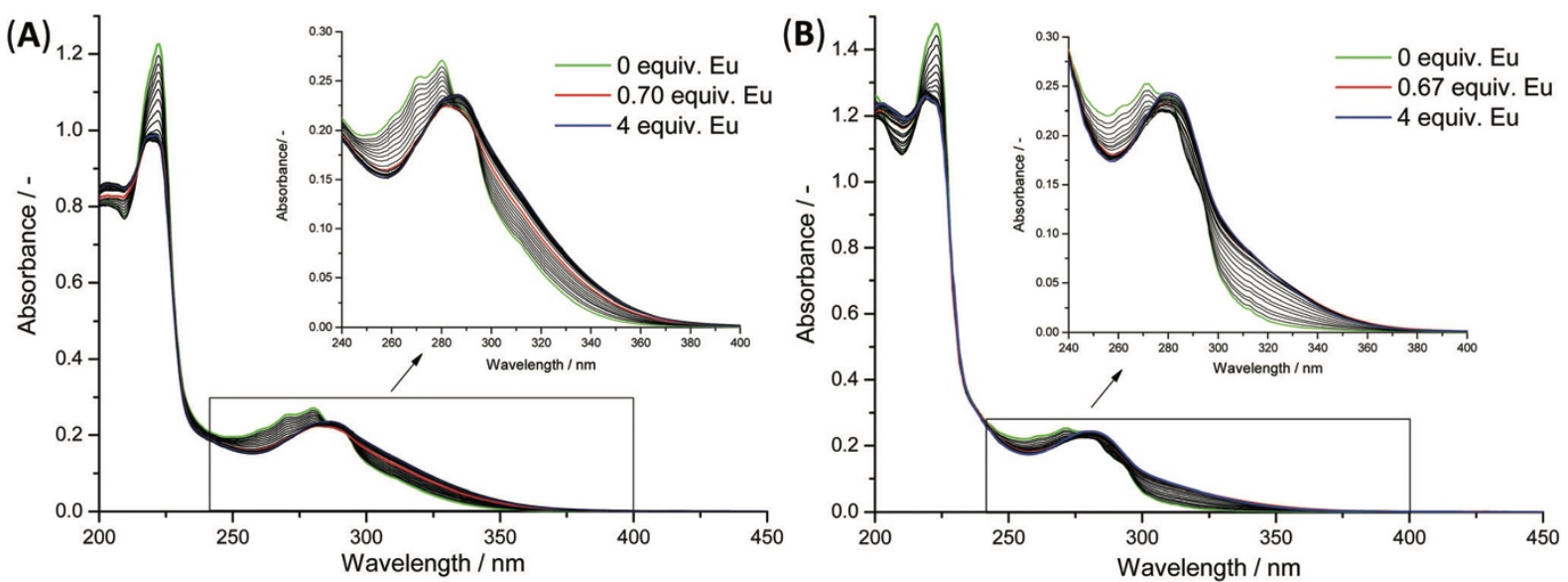

Fig. 1 The changes in the absorption spectrum of ligands $(A) 4(R, R)(c=7.84 \times 10-6 \mathrm{M})$ or

(B) $5(\mathrm{~S}, \mathrm{~S})(\mathrm{c}=1.00 \times 10-5 \mathrm{M})$ upon addition of $\mathrm{Eu}(\mathrm{OTf}) 3(0 \rightarrow 4$ equiv. $)$ in $\mathrm{CH} 3 \mathrm{CN}$ at 25 ${ }^{\circ} \mathrm{C}$.

Self-assembly studies between chiral ligands 3-6 and Eu(III) ions in solution, formation of helical assemblies at low concentration using UV-Vis and luminescence spectroscopy Initially, the absorption spectra of the ligands developed herein, were evaluated in $\mathrm{CH} 3 \mathrm{CN}$ solution (Fig. S15†). The same trend was seen for all, where two main absorption bands centred at ca. $223 \mathrm{~nm}$ and $280 \mathrm{~nm}$ were observed, these being assigned to $\pi \rightarrow \pi^{*}$ and $\mathrm{n} \rightarrow \pi^{*}$ transitions within ligands structure $(\varepsilon 280(3(\mathrm{~S}, \mathrm{~S}))=34553 \mathrm{M}-1 \mathrm{~cm}-1, \varepsilon 280(4(\mathrm{R}, \mathrm{R}))=34963$ $\mathrm{M}-1 \mathrm{~cm}-1, \varepsilon 280(5(\mathrm{~S}, \mathrm{~S}))=23260 \mathrm{M}-1 \mathrm{~cm}-1$ and $\varepsilon 280(6(\mathrm{R}, \mathrm{R}))=23358 \mathrm{M}-1 \mathrm{~cm}-1)$. The self-assembly studies between the ligands $3-6$ and $\mathrm{Eu}(\mathrm{III})$ ions in $\mathrm{CH} 3 \mathrm{CN}$ solution were next monitored by following the changes in the absorption, fluorescence and $\mathrm{Eu}(\mathrm{III})$-centred 
emission spectra of each ligand upon gradual addition of metal ions $(0 \rightarrow 4$ equivalents) (Fig. 1). The changes in the titration profiles for the pair of enantiomers $3(S, S), 4(R, R)$ and $5(S, S)$, $6(R, R)$ followed the same trends, and therefore, we will only discuss one of each sets of enantiomers herein. The changes in the absorption spectra of $4(R, R)$ and $5(S, S)$ are shown in Fig. 1A and B; the long absorption wavelength being red shifted upon complexation of these ligands with $\mathrm{Eu}(\mathrm{III})$. The changes observed for $3(\mathrm{~S}, \mathrm{~S})$ and $6(\mathrm{R}, \mathrm{R})$ upon addition of $\mathrm{Eu}(\mathrm{III})(0$ $\rightarrow 4$ equiv.) were to greater extend identical; the main differences being the observation of a less decrease in the absorbance centred at $222 \mathrm{~nm}$ between the additions of $0 \rightarrow 0.50$ equivalents of $\mathrm{Eu}(\mathrm{III})$, and higher hyperchromicity of the band centred at $334 \mathrm{~nm}$ in the case of $5(\mathrm{~S}, \mathrm{~S})$ and $6(\mathrm{R}, \mathrm{R})$ com- pared to $3(\mathrm{~S}, \mathrm{~S})$ and $4(\mathrm{R}, \mathrm{R})$ (Fig. $1 \mathrm{~A}$ and $\mathrm{B})$. This can reflect the differences in the conformational changes between the self- assembly processes in solution. In both cases the changes in the absorption bands of the ligand occurred until addition of 0.67 equivalents of $\mathrm{Eu}(\mathrm{III})$ when the plateau has been reached (Fig. S16, S17, S21 and S24†). Excitation into the naphthalene bands at $\lambda \mathrm{ex}=281 \mathrm{~nm}$ resulted in a weak ligand-centred emission with the maximum at $\sim 425-460 \mathrm{~nm}$ for all the ligands (Fig. S18, S19, S22 and S25†). Upon addition of $\mathrm{Eu}(\mathrm{III})(0 \rightarrow 0.67$ equivalents $)$ an enhancement was seen in the ligand-centred emission of the benzene-1,3-diamine linker based ligands $3(\mathrm{~S}, \mathrm{~S})$ and $4(\mathrm{R}, \mathrm{R})$, while after the addition of 0.67 equivalents of $\mathrm{Eu}(\mathrm{III})$, a gradual decrease in the ligandcentred emission was observed. Concomitantly, the Eu(III)-centred emission was observed, indicating the successful population of the lanthanide excited state, through sensitisation of the naphthalene antennae, with the maximum of luminescence intensity being achieved upon the addition of ca. 0.70 equivalents of $\mathrm{Eu}(\mathrm{III})$. Upon further additions, a decrease in the lanthanide luminescence was observed until it reached plateau after the addition of ca. 1.25 equivalents (Fig. S18 and S22). The case of increasing ligand centred emission upon complexation with $\mathrm{Eu}(\mathrm{III})$ is unusual and suggests the presence of strong interaction between 
the ligands as well as decrease of vibration quenching effects within ligand structure occurring upon complexation.16 In the case of 5(S,S) and 6(R,R) (with 4,4'-(cyclohexane1,1-diyl)bis (2,6-dimethylaniline) linker) 17 the weak ligand centred fluorescence decreased upon complexation with $\mathrm{Eu}(\mathrm{III})$. At the same time, the $\mathrm{Eu}(\mathrm{III})$-centred emission appears; reaching maximum upon addition of 0.67 equivalents of $\mathrm{Eu}(\mathrm{III})$. After this point, the ligandcentred emission is gradually enhanced, while $\mathrm{Eu}(\mathrm{III})$-centred emission decreased until 4 equivalents of the ion added (Fig. S19 and S25 $\dagger$ ). The changes in the delayed $(0.10 \mathrm{~ms})$ $\mathrm{Eu}(\mathrm{III})$-centred emission were following the same trend as these observed in the fluorescence spectra earlier (Fig. 2, S20, S23 and S26 $†$ ). The ratio between the 5D0 $\rightarrow$ 5FJ transitions for these two sets of diamine linkers varies significantly, suggesting discrepancy in the coordination environment of $\mathrm{Eu}(\mathrm{III})$ ion. Interestingly, the ratio between the species formed in solution also varies, which is a sign that different self-assembly processes are occurring in solution for these two types of ligands. However, in both cases, the presence of 5D0 $\rightarrow$ 7F0 band is observed, this suggesting the formation of species where the Eu(III) ions are within a site symmetry of $\mathrm{Cnv}, \mathrm{Cn}$ or Cs. 18 In contrast to these titrations, the titration profile for 3(S,S) and 4(R,R) (with benzene-1,3-diamine linker) upon titration with Eu(III) corresponds closer to the behaviour previously observed for $1(\mathrm{~S}, \mathrm{~S})$ and $2(\mathrm{R}, \mathrm{R})$ (with 1,3-phenylenedimethanamine). $8 \mathrm{c}$ In all the cases the shape of the excitation spectra with $\lambda$ max at $280 \mathrm{~nm}$ recorded during the course of the titrations $(\lambda \mathrm{em}=616 \mathrm{~nm}$; Fig. S27 $\dagger)$ confirmed that the population of the $\mathrm{Eu}(\mathrm{III})$ excited state occurs via the "antenna effect" where the energy absorbed by the ligands is transferred onto the metal centres from where the characteristic sharp line-like emission occurs. During the course of the titration the lifetimes of the 5D0 level of $\mathrm{Eu}(\mathrm{III})$ were recorded upon the addition of 0.67 eq. and these results were then best fitted to mono-exponential decays with the average values of $\sim 1.50-1.70 \mathrm{~ms}$ suggesting the formation of fully saturated metal coordination spheres (Fig. S28†).8a,b,19a,b 
The changes observed during the course of these titrations were analysed by fitting the data using non-linear regression analysis program SPECFIT.20 In all the cases, the factor analysis suggested the formation of three additional species along with the initial ligand being present in solution. The stability constants were determined (as $\log \beta \mathrm{ML}$ ) for the binding models [Eu:L2], [Eu2:L2] and [Eu2:L3] (Table 1). The values of the binding constants between the enantiomers of the same ligand closely corresponded to each other, and were found to be higher for the ligands consisting of smaller linker groups such as $(1(\mathrm{~S}, \mathrm{~S}), 2(\mathrm{R}, \mathrm{R})) 8 \mathrm{c}$ and $(3(\mathrm{~S}, \mathrm{~S}), 4(\mathrm{R}, \mathrm{R}))$ compared to $(5(\mathrm{~S}, \mathrm{~S}), 6(\mathrm{R}, \mathrm{R}))$ (Table 1). The speciation distribution diagram for these titrations also revealed that the yield of [Eu2:L3] species at 0.67 equiv. of Eu(III) decreased from $80.2 \%$ for $1(S, S), 2(R, R) 8 c$ and $82.5 \%$ for $3(S, S), 4(R, R)$ to $72.2 \%$ for 5(S,S), 6(R,R), Fig. S29.†

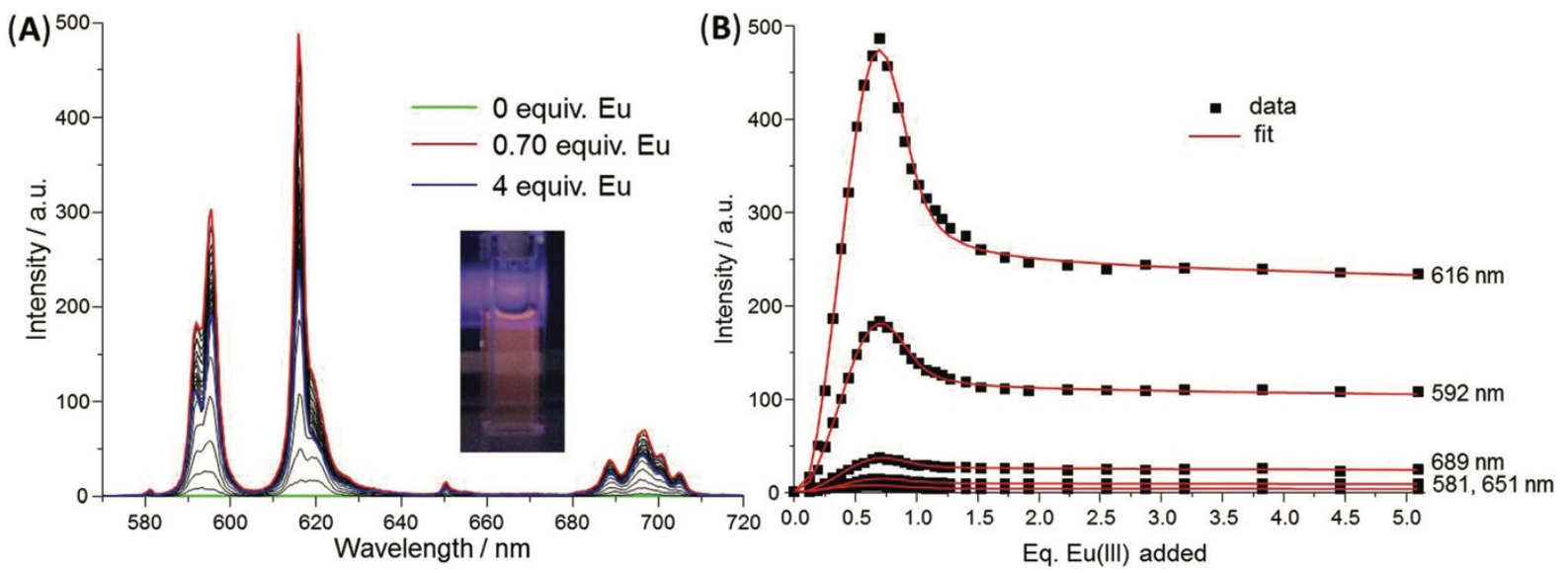

Fig. 2 (A) The changes in the delayed Eu(III)-centred emission spectrum of $4(\mathrm{R}, \mathrm{R})(\mathrm{c}=7.84$ $\times 10-6 \mathrm{M})$ upon addition of $\mathrm{Eu}(\mathrm{OTf}) 3(0 \rightarrow 4$ equiv. $)$ in $\mathrm{CH} 3 \mathrm{CN}$ at $\mathrm{T}=25^{\circ} \mathrm{C}, \lambda \mathrm{ex}=281 \mathrm{~nm}$ (total decay time $=0.02 \mathrm{~s}$; delay time $=0.1 \mathrm{~ms}$ ); $(\mathrm{B})$ experimental binding isotherms for the same titration and their corresponding fits by means of SPECFIT program. 


\section{Circular dichroism (CD) and circularly polarised luminescence (CPL) for [Eu2:L3] assemblies in solution}

The chiral nature of the ligands was probed using CD spectroscopy, and the Cotton effects in the spectra of corresponding pair of enantiomers (e.g. 3(S,S), 4(R,R) and 5(S,S), 6(R,R)) appeared as mirror images to each other, Fig. 3. For 3(S,S), three positive CD signals were observed with the maxima at ca. 296, 229, $208 \mathrm{~nm}$ along with two negative CD signals at 271 and $219 \mathrm{~nm}$. The signals in the CD spectra of $5(\mathrm{~S}, \mathrm{~S})$ were similar to these observed for $3(\mathrm{~S}, \mathrm{~S})$ with the positive signals observed at 285, 230 and $209 \mathrm{~nm}$, correspondingly, while showing only one negative signal at $223 \mathrm{~nm}$. The shape of the CD spectra observed here closely corresponds to similar structures previously developed.8a,b

The corresponding [Eu2:L3] were then formed in solution through self-assembly of 1 equiv. of the corresponding ligand with 0.67 equiv. of $\mathrm{Eu}(\mathrm{III})$. Each solution was then equilibrated for 15 minutes to ensure the formation of the desired [Eu2:L3] helical assemblies in solution (Fig. 3). Again the spectra corresponding to each pair of enantiomers appeared as mirror image to one another suggesting enantiomeric purity of the corresponding $\mathrm{Eu}(\mathrm{III})$ species (although this might also represent a minor contribution from other stoichiometries as outlined above). The CD spectra of the complexes appeared significantly different to those of the ligands. For example, for [Eu2:L3] with $\mathrm{L}=3(\mathrm{~S}, \mathrm{~S})($ Fig. 3A) the first negative Cotton effect band was observed at $325 \mathrm{~nm}$ while second positive Cotton effect band at $295 \mathrm{~nm}$ and an amplitude of 4.6 mdeg showing negative chirality. The following positive Cotton effect centred at $227 \mathrm{~nm}$ and negative Cotton effect at 214 appeared with large amplitude of 115 mdeg. The presence of sinusoid-like shape of the CD spectra for [Eu2:L3] suggests the appearance of possible mixing between electric- and magnetic-dipole allowed transitions (most likely exciton coupling) between the chromophores that has been brought in one another close proximity due to the formation of the $\mathrm{Eu}(\mathrm{III})$ assemblies.21 Similarly, for 
[Eu2:L3] complexes where $\mathrm{L}=5(\mathrm{~S}, \mathrm{~S})$ (Fig. 3B), the first negative Cotton effect was observed at $340 \mathrm{~nm}$, with the following positive Cotton effect being observed at $295 \mathrm{~nm}$ and the amplitude of 3 mdeg. The latter positive Cotton effect then evolved into the next positive $\mathrm{CD}$ band centred at $227 \mathrm{~nm}$ with the following negative Cotton effect at $212 \mathrm{~nm}$ and the amplitude of 245 mdeg. Similarities in the shape of the CD spectra between [Eu2:L3] (L = 3(S,S), 4(R,R); Fig. 3A) and (L = 5(S,S), 6(R,R); Fig. 3B) suggests similar geometrical character of the assemblies being formed in $\mathrm{CH} 3 \mathrm{CN}$.

Table 1 Binding constants (log $\beta \mathrm{M}: \mathrm{L})$ obtained by fitting the changes in absorption, fluorescence and $\mathrm{Eu}(\mathrm{III})$-centred emission spectra of $3(\mathrm{~S}, \mathrm{~S}), 4(\mathrm{R}, \mathrm{R}), 5(\mathrm{~S}, \mathrm{~S})$ or $6(\mathrm{R}, \mathrm{R})$ upon addition of $\mathrm{Eu}(\mathrm{CF} 3 \mathrm{SO} 3) 3 \mathrm{in} \mathrm{CH} 3 \mathrm{CN}$ solution $\left(25^{\circ} \mathrm{C}\right)$. All titrations were done at least in triplicates

\begin{tabular}{|c|c|c|c|c|c|c|c|c|c|}
\hline \multirow[b]{2}{*}{$\mathrm{Eu}(\mathrm{m})$} & \multicolumn{3}{|c|}{ Absorbance } & \multicolumn{3}{|c|}{ Fluorescence } & \multicolumn{3}{|c|}{$\mathrm{Eu}(\mathrm{III})$-Centred emission } \\
\hline & $\log \beta_{1: 2}$ & $\log \beta_{2: 3}$ & $\log \beta_{2: 2}$ & $\log \beta_{1: 2}$ & $\log \beta_{2: 3}$ & $\log \beta_{2: 2}$ & $\log \beta_{1: 2}$ & $\log \beta_{2: 3}$ & $\log \beta_{2: 2}$ \\
\hline $\mathbf{L}=\mathbf{3}(S, S)$ & $13.7^{a}$ & $26.7 \pm 0.2$ & $19.6 \pm 0.2$ & $13.3 \pm 0.4$ & $26.6 \pm 0.5$ & $19.6 \pm 0.4$ & $13.2 \pm 0.4$ & $27.9 \pm 0.2$ & $21.2 \pm 0.1$ \\
\hline $\mathbf{L}=\mathbf{4}(R, R)$ & $12.5 \pm 0.4$ & $26.4 \pm 0.3$ & $19.1 \pm 0.2$ & $13.2^{a}$ & $27.1 \pm 0.2$ & $20.7 \pm 0.1$ & $13.2 \pm 0.1$ & $26.6 \pm 0.2$ & $20.7 \pm 0.1$ \\
\hline $\mathbf{L}=\mathbf{5}(S, S)$ & $12.7 \pm 0.1$ & $25.5 \pm 0.3$ & $18.1 \pm 0.2$ & $14.3 \pm 0.3$ & $26.2 \pm 0.3$ & $19.2 \pm 0.2$ & $13.9 \pm 0.2$ & $26.2 \pm 0.4$ & $19.1 \pm 0.1$ \\
\hline $\mathbf{L}=\mathbf{6}(R, R)$ & $12.9 \pm 0.1$ & $25.4 \pm 0.3$ & $19.3 \pm 0.2$ & $15.0 \pm 0.2$ & $28.5 \pm 0.3$ & $20.3 \pm 0.3$ & $13.9 \pm 0.2$ & $25.8 \pm 0.6$ & $19.9 \pm 0.3$ \\
\hline
\end{tabular}

a Values were fixed to allow convergence of the experimental data to the proposed model.
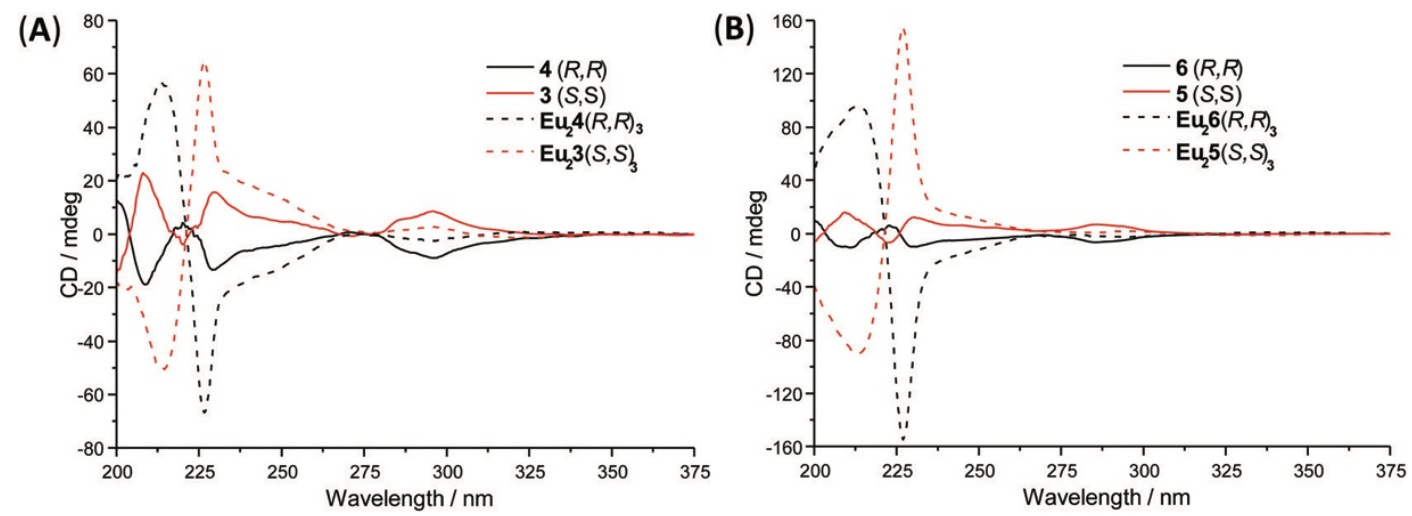
Fig. 3 Circular dichroism spectra of the ligands $(A) L=3(S, S), 4(R, R)(c=1.43 \times 10-5 M)$ and $(B) \mathrm{L}=5(\mathrm{~S}, \mathrm{~S}), 6(\mathrm{R}, \mathrm{R})(\mathrm{c}=1.40 \times 10-5 \mathrm{M})$ together with their corresponding Eu2L3 complexes $(\mathrm{cEu} 2 \mathrm{~L} 3=4.77 \times 10-6 \mathrm{M})$ in $\mathrm{CH} 3 \mathrm{CN}$.

The changes in the CD spectra can be used to correlate the nonlinear enhancement of the chiroptical response to the non- linearity dependence on point chirality for tetrahedral Eu(III) chiral cage structures or used to monitor anion sensing events for different anions in solution.7b,12c Furthermore, in our previous work, 22 we have shown that the changes in the CD spectra of chiral ligands titrated with Ln(III) ions can be used not only to monitor the structural/conformational changes occurring upon complexation/self-assembly formation, but also used to evaluate the binding affinities between the ligands and the ions in solution by fitting the data using non- linear regression analysis. With this in mind, we monitored the changes in the $C D$ spectra of the ligands $L=5(S, S)$ and $6(R, R)$, upon addition of $E u(I I I)(0$ $\rightarrow 4$ equiv.). From these titrations, Fig. 4 , it was clear that a significant structural conformations occurred upon formation of the helicates in solution, and the presence of a kinetic effects was also observed.23 As previously observed for CD spectra of the ligands and their assemblies with $\mathrm{Eu}(\mathrm{III})$ (Fig. 3) the titrations profile for 5(S,S) was a mirror image to that observed for 6(R,R) (Fig. 4), and the binding isotherms (Fig. S30 $\dagger$ ) reveal the main changes in the spectra happening until the addition of 0.67 equiv. of Eu(III) (Table 1), supporting the formation of the bi-metallic triple- stranded helicates in solution. Finally, the CPL spectra of [Eu2:L3] assemblies were recorded in $\mathrm{CH} 3 \mathrm{CN}$ solution, where the Eu(III) centred emission was monitored upon ligand excitation (Fig. 5). This clearly revealed the chiral nature of the Eu(III) centres; each pair of enantiomers resulted in CPL 
spectra that were mirror images opposite in signs and equal in magnitudes. The absolute configuration of $\mathrm{Eu}(\mathrm{III})$ centres can be tentatively assigned by comparing these results to the CPL spectra of previously published mononuclear Eu(III) complexes, where the absolute configuration was determined by using X-ray crystallography.19 As such, the [Eu2:L3] selfassemblies where $\mathrm{L}=3(\mathrm{~S}, \mathrm{~S}), 5(\mathrm{~S}, \mathrm{~S})$ can be assigned as being $\Delta, \Delta$ around the two metal ions, while for $L=4(R, R), 6(R, R)$, the assignment of the absolute configuration is $\Lambda, \Lambda$. The dissymmetry factors (glum) are listed in Table 2 and represented in the g-value plots on Fig. $\mathrm{S} 31 . \dagger$ The $5 \mathrm{D} 0 \rightarrow 7 \mathrm{~F} 1$ transition of these were determined to be of similar values observed for other reported mono-metallic complexes and di-metallic helicates.19a,b,12c The exception, however, being the bulkier ligands $5(\mathrm{~S}, \mathrm{~S})$ and $6(\mathrm{R}, \mathrm{R})$ which gave lower glum values. The glum values determined for the $5 \mathrm{D} 0 \rightarrow 7 \mathrm{~F} 2$ transitions were also found to be similar to the mono- metallic Eu(III) "Trinity Sliotar" bundles, previously developed in our group.19a In comparison to these results, the $\mathrm{L}=3(\mathrm{~S}, \mathrm{~S}), 4(\mathrm{R}, \mathrm{R})$ assemblies showed relatively high glum values for the 5D0 $\rightarrow$ 7F3 transition; being $0.40-0.60$, which is among the highest reported for this kind of structures. Additionally reasonably high glum values were observed for the 5D0 $\rightarrow$ 7F4 transition; being $0.45-0.53$ for $[\mathrm{Eu} 2: \mathrm{L} 3](\mathrm{L}=3(\mathrm{~S}, \mathrm{~S}), 4(\mathrm{R}, \mathrm{R}))$ and $\sim 0.45$ for [Eu2:L3] $(\mathrm{L}=5(\mathrm{~S}, \mathrm{~S}), 6(\mathrm{R}, \mathrm{R}))($ Table 2$)$. Such relatively 57 high glum( D0 $\rightarrow$ F3) values might be a sign of strong J-mixing and a strong crystal-field perturbation in these triple-stranded helicates. $18 \mathrm{~b}$ 

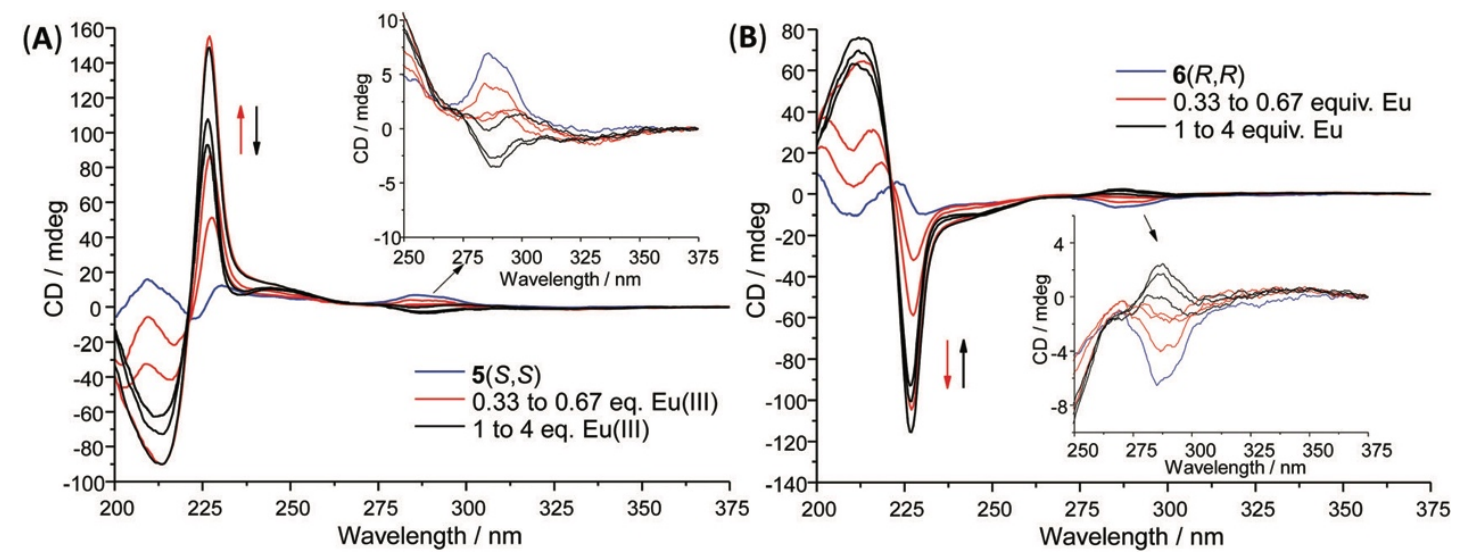

Fig. 4 The changes in the CD spectra of (A) $5(\mathrm{~S}, \mathrm{~S})(\mathrm{c}=1.40 \times 10-5 \mathrm{M})$ and $(\mathrm{B}) 6(\mathrm{R}, \mathrm{R})(\mathrm{c}=$ $1.34 \times 10-5 \mathrm{M})$ upon addition of $\mathrm{Eu}(\mathrm{OTf}) 3(0 \rightarrow 4$ equiv. $)$ in $\mathrm{CH} 3 \mathrm{CN}$.
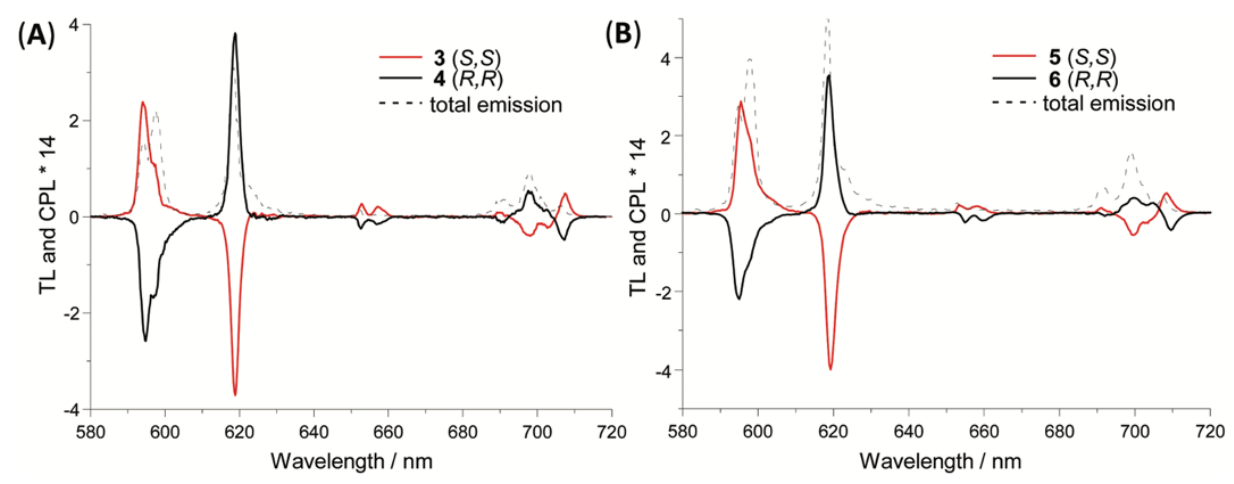

Fig. 5 Circularly polarised luminescence spectra and total luminescence emission of Eu2L3 complexes in $\mathrm{CH} 3 \mathrm{CN}(\mathrm{c}=3.33 \times 10-5 \mathrm{M})$ where $\mathrm{L}$ is $(\mathrm{A}) 3(\mathrm{~S}, \mathrm{~S}), 4(\mathrm{R}, \mathrm{R})$ and $(\mathrm{B}) \mathrm{L}=5(\mathrm{~S}, \mathrm{~S})$, $6(\mathrm{R}, \mathrm{R})(\lambda \mathrm{ex}=281 \mathrm{~nm})$.

Table 2 Dissymmetry factor values (glum) determined from the spectra depicted on Figure 3 


\begin{tabular}{llcrrr} 
Transition & $\lambda, \mathrm{nm}$ & $g_{\text {lum }}\left(\mathbf{E u}_{2}(3(S, S))_{3}\right)$ & $g_{\text {lum }}\left(\mathbf{E u}_{2}(\mathbf{4}(R, R))_{3}\right)$ & $g_{\text {lum }}\left(\mathbf{E u}_{2}(5(S, S))_{3}\right)$ & $g_{\text {lum }}\left(\mathbf{E u}_{2}(\mathbf{6}(R, R))_{3}\right)$ \\
\hline${ }^{5} \mathrm{D}_{0} \rightarrow{ }^{7} \mathrm{~F}_{1}$ & 595 & 0.27 & -0.27 & 0.17 & -0.17 \\
${ }^{5} \mathrm{D}_{0} \rightarrow{ }^{7} \mathrm{~F}_{1}$ & 603 & 0.19 & -0.27 & 0.18 & -0.16 \\
${ }^{5} \mathrm{D}_{0} \rightarrow{ }^{7} \mathrm{~F}_{2}$ & 620 & -0.27 & 0.28 & -0.21 & 0.20 \\
${ }^{5} \mathrm{D}_{0} \rightarrow{ }^{7} \mathrm{~F}_{3}$ & 654 & 0.43 & -0.50 & 0.20 & -0.26 \\
${ }^{5} \mathrm{D}_{0} \rightarrow{ }^{7} \mathrm{~F}_{3}$ & 658 & 0.57 & -0.61 & 0.32 & -0.32 \\
${ }^{5} \mathrm{D}_{0} \rightarrow{ }^{7} \mathrm{~F}_{4}$ & 696 & -0.06 & 0.06 & -0.03 & 0.05 \\
${ }^{5} \mathrm{D}_{0} \rightarrow{ }^{7} \mathrm{~F}_{4}$ & 700 & -0.08 & 0.09 & -0.06 & 0.05 \\
${ }^{5} \mathrm{D}_{0} \rightarrow{ }^{7} \mathrm{~F}_{4}$ & 704 & -0.08 & -0.09 & -0.07 & 0.45 \\
${ }^{5} \mathrm{D}_{0} \rightarrow{ }^{7} \mathrm{~F}_{4}$ & 710 & 0.53 & -0.52 & 0.45
\end{tabular}

Table 3 Overall europium-centred luminescence quantum yields and sensitisation efficiencies for [Eu2L3] helicate complexes recorded in CH3CN.24

\begin{tabular}{llllll}
\hline $\mathrm{Eu}_{2} \mathrm{~L}_{3}$ & $\tau_{\text {obs }}, \mathrm{ms}$ & $\Phi_{\text {tot }}, \%$ & $\tau_{\mathrm{R}}, \mathrm{ms}$ & $\Phi_{\mathrm{Ln}}^{\mathrm{Ln}}, \%$ & $\eta_{\text {sens }}, \%$ \\
\hline $\mathbf{L}=\mathbf{1}(S, S)$ & $1.44 \pm 0.01$ & $5.8 \pm 0.1$ & $6.9 \pm 0.4$ & $21.0 \pm 0.5$ & 27.6 \\
$\mathbf{L}=\mathbf{4}(R, R)$ & $1.48 \pm 0.01$ & $3.2 \pm 0.5$ & $10.4 \pm 0.7$ & $14.3 \pm 0.8$ & 22.4 \\
$\mathbf{L}=\mathbf{5}(\mathrm{S}, \mathrm{S})$ & $1.43 \pm 0.03$ & $2.6 \pm 0.1$ & $9.4 \pm 0.8$ & $15.3 \pm 0.9$ & 17.0
\end{tabular}

$\eta$ sens - antenna-to-ion energy transfer efficiencies, $\tau$ obs - the observed luminescence lifetime, $\Phi$ tot - the experimental overall luminescence quantum yield $(\lambda=279 \mathrm{~nm}), \tau-$ the radiative lifetime, $\Phi \mathrm{Ln}$ - the ex R Ln intrinsic quantum yield of lanthanide.

\section{Photophysical properties of [Eu2:L3] assemblies in solution}

The photophysical properties of the triple stranded di-metallic helicates [Eu2:L3], were monitored in solution upon the self- assembly formation in real time. These were seen to be close to identical for each pairs of enantiomers, therefore we report herein, only the photophysical results for one of each enantiomers (Table 3 and Fig. S32 $\dagger$ ). For these complexes, the life- times were recorded in solution by monitoring the decay of the $\mathrm{Eu}(\mathrm{III})$ $5 \mathrm{D} 0 \rightarrow 7 \mathrm{~F} 2$ band upon ligand excitation at $279 \mathrm{~nm}$. In all the cases, the lifetime decay curves were best fitted to mono- exponential decay using Origin9.1®; the values being practically the same, ca. $1.45 \mathrm{~ms}$, for all the complexes (Scheme 1), which also corresponds to the lifetime values obtained for the addition of 0.67 equivalents of metal ion to the solution. This 
suggest the presence of one type of coordination environment around $\mathrm{Eu}(\mathrm{III})$ ion in solution (Table 3 and Fig. S33†). The total quantum yield (Фtot) of the Eu(III) emission was also determined for these self-assembly species. The results showed that Фtot was two times higher for $[\operatorname{Eu} 2(1(\mathrm{~S}, \mathrm{~S})) 3]$ than $[\operatorname{Eu} 2(4(\mathrm{R}, \mathrm{R})) 3]$ and $[\operatorname{Eu} 2(5(\mathrm{~S}, \mathrm{~S})) 3]$. The values of the radiative lifetime $(\tau R)$, the intrinsic quantum yield $(\Phi \mathrm{Ln})$ and the antenna-to-ion energy Ln transfer efficiencies ( $\eta$ sens) calculated for Eu(III) assemblies using their emission spectra, the observed luminescence lifetime ( $\tau$ obs), and $\Phi$ tot suggests that non-radiative processes was most apparent for $L=1(S, S)$. However, as the same system reveals the highest $\Phi L n$ and $\eta$ in comparison to the other Ln sens two systems means that the radiative processes in this case compete well with non-radiative ones. This can be due to the better sensitisation efficiency thanks to the ligand structure allowing the position of triplet state level relative to $\mathrm{Eu}(\mathrm{III})$ levels as well as better geometrical arrangement of the ligand around the metal ion.1,25

\section{Mass-spectrometry analysis of [Eu2:L3] assemblies}

Mass-spectrometry analyses were performed using [Eu2:L3] complexes formed under thermodynamic control by reacting 1 equiv. of the respective $\mathrm{L}$ with 0.67 equiv. of $\mathrm{Eu}(\mathrm{ClO} 4) 3\left(50 \mathrm{wt} \%\right.$ in water) in $\mathrm{CH} 3 \mathrm{OH}$ at $65^{\circ} \mathrm{C}$ under microwave irradiation for 2 hours. The complexes were precipitated out of solution using ether diffusion, dried under vacuum before being subjected to matrix-assisted laser desorption/ionisation mass-spectrometry (MALDI-MS) with DCTB used as matrix (Fig. 6 and S34-S37†). For the Eu(III) samples investigated in this work the presence of [Eu:L], [Eu2:L], [Eu:L2], [Eu2:L2] species was observed. At the same time [Eu2:L3] species were only observed for the samples with ligands $\mathrm{L}=3(\mathrm{~S}, \mathrm{~S})$ and $4(\mathrm{R}, \mathrm{R})$. The presence of tri-metallic species was also observed for complexes with $\mathrm{L}=3(\mathrm{~S}, \mathrm{~S})[\mathrm{Eu} 3: \mathrm{L} 3]$. The samples with $\mathrm{L}=6(\mathrm{R}, \mathrm{R})$ also resulted in the assignment of a [Eu3:L2] species, suggesting possible formation of more complex systems, but such higher 
order systems have been reported in the literature by others, 12 believed to be due to supramolecular cooperativity effects.23b,26 Unfortunately, we were unable to get reliable MS or HRMS results when using samples from the various spectroscopic titrations discussed above, this most likely being due to low concentrations of these assemblies in these samples.

\section{H NMR study of the self-assembly between L and Eu(III)}

We also investigated the formation of these helicates in solution by observing the changes in the $1 \mathrm{H}$ NMR of the ligands. Unlike commonly seen for many other lanthanide complexes (such as cyclen based macrocyclic complexes), the changes in the NMR of the systems studied here upon addition of the lanthanides, occurred over relatively narrow range, and with less signal broadening, allowing for the formation of these assemblies to be monitored in real-time. The solutions of $4(R, R)$ and $6(R, R)(c=1.00 \times 10-3 M)$ were titrated against gradual addition of $\mathrm{Eu}(\mathrm{CF} 3 \mathrm{SO} 3) 3(0 \rightarrow 1.99$ or $0 \rightarrow 1.11$ equiv., correspondingly) in CD3CN. In case of 4(R,R) (Fig. 7 and S38†), noticeable changes started to occur upon addition of 0.22 equiv. of $\mathrm{Eu}(\mathrm{III})$, and these continued until the addition of 0.66 equiv., after which no significant changes were observed within the aromatic region. This confirming the successful formation of the [Eu2:43] in solution at these concentrations. Furthermore, we also observed that a resonance assigned to water, that was present in the solution of $4(R, R)$ at 2.13 ppm, experienced a significant upfield shift to 1.74 ppm (Fig. S39†) suggesting a possible encapsulation of water within the helicate. As we anticipate a full saturation around the two lanthanide ions (by the three ligand strands), it is possible that the water molecule is located within a cavity, that is generated at the centre of the structure where the three bridges are located. However, in the absence of a crystal structure of this [Eu2:L3] assembly, this cannot be fully determined. The $1 \mathrm{H}$ NMR spec- trum was recorded for $\mathrm{Eu}(\mathrm{III})$ complex with $\mathrm{L}=$ 3(S,S) syn- thesised under thermodynamic control and its shape closely resembles the 
spectrum observed for 0.66 equiv. addition of $\mathrm{Eu}(\mathrm{III})$ ion to the ligand during the titration (Fig. S40 $\dagger$ ) there- fore confirming the formation of [Eu2:L3] in both cases together with MALDI-MS data. In contrast to these results, then upon addition of $\mathrm{Eu}(\mathrm{CF} 3 \mathrm{SO} 3) 3$ to $6(\mathrm{R}, \mathrm{R})$ significant broad- ening was observed for most of the characteristic signals in the $1 \mathrm{H}$ NMR spectrum beyond the addition of 0.44 equiv. of $\mathrm{Eu}(\mathrm{III})$, making it impossible to distinguish between these signals (Fig. S41†). However, similarly to the aforementioned titration it was possible to follow the changes of the water peak where it started to shift upon addition of 0.66 equiv. of $\mathrm{Eu}(\mathrm{III})$ due to the possible encapsulation within [Eun:Lm] assemblies (Fig. S42 $\dagger$ ). The broadening of the $1 \mathrm{H}$ NMR spectra during the self-assembly process between $6(\mathrm{R}, \mathrm{R})$ and $\mathrm{Eu}(\mathrm{III})$ occurs most likely due to the similar exchange rate between metal and ligand during complexation compared to the NMR time scale, which could be directly related to the size of the central spacer unit.27 The signals in the $1 \mathrm{H}$ NMR spectrum of $\mathrm{Eu}(\mathrm{III})$ complex with $\mathrm{L}=5(\mathrm{~S}, \mathrm{~S})$ made under thermodynamic control revealed broad signals similarly to the titration data and along with the exchange rate this can occur due to the steric hindrance of the ligand during the assembly processes (Fig. S43†). However, as the solution of the complex was heated up to $40{ }^{\circ} \mathrm{C}$ and then cooled down to $22{ }^{\circ} \mathrm{C}$ it became more resolved (Fig. S44 $\dagger$ ) as heating increased the reaction rate shifting the equilibrium from $\mathrm{L}$ and $\mathrm{Eu}(\mathrm{III})$ towards the formation of highly symmetrical [Eu2:L3] $(\mathrm{L}=5(\mathrm{~S}, \mathrm{~S}))$ species.27
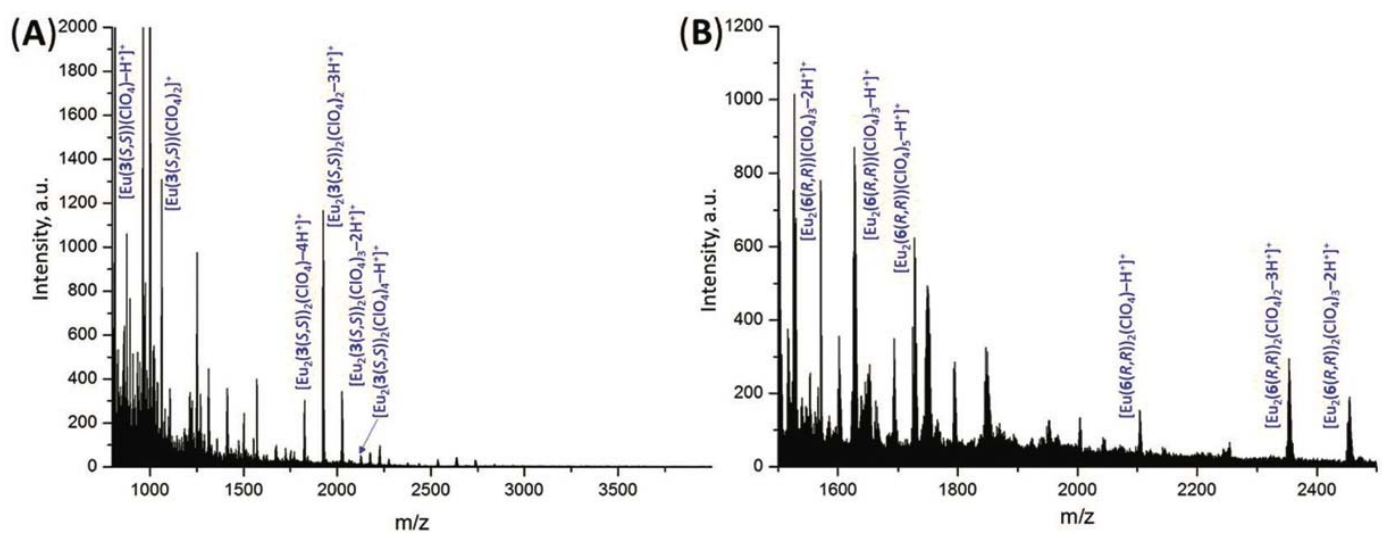
Fig. 6 MALDI-MS spectra of Eu(III) complexes with (A) $L=3(S, S),(B) L=6(R, R)$.

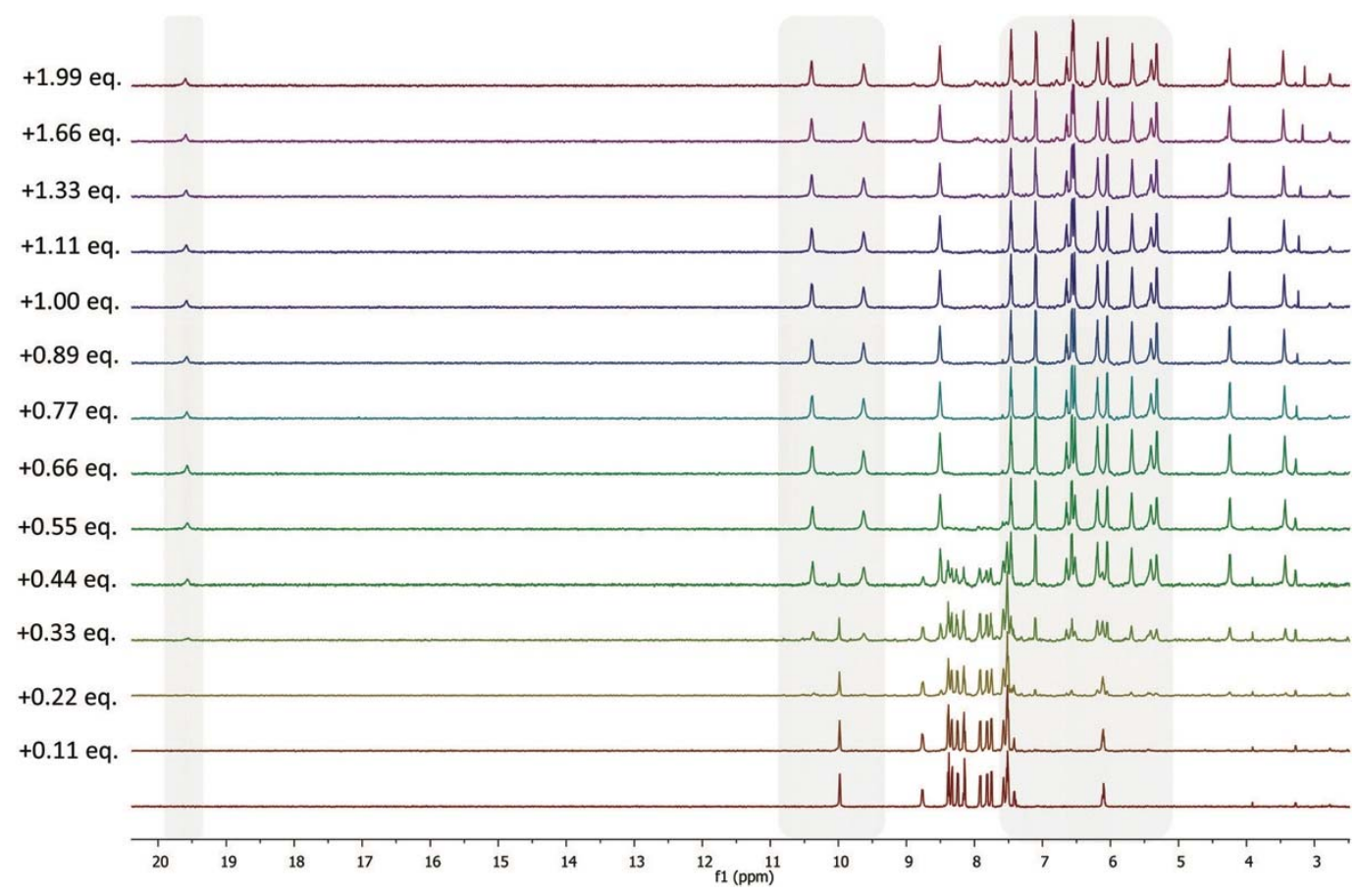

Fig. 7 The changes in $1 \mathrm{H}$ NMR of $4(\mathrm{R}, \mathrm{R})\left(\mathrm{c}=1.00 \times 10^{-3} \mathrm{M}\right)$ upon addition of $\mathrm{Eu}(\mathrm{CF} 3 \mathrm{SO} 3) 3(0 \rightarrow 1.99$ equiv. $)$ in $\mathrm{CD} 3 \mathrm{CN}\left(600 \mathrm{MHz}, \mathrm{T}=25^{\circ} \mathrm{C}\right)$.

\section{Conclusions}

In conclusion we have synthesised four new ligands by coup- ling the diamine linker of various size with two chiral half-helicate ligands. The titrations of these at low concentration upon addition of $\mathrm{Eu}(\mathrm{III})$ in $\mathrm{CH} 3 \mathrm{CN}$ allowed us to determine the binding constants values for [Eu:L], [Eu2:L2] and [Eu2:L3] self- assembly species. Lower values of the binding constants were found for the systems with the bulkier spacer $5(\mathrm{~S}, \mathrm{~S}), 6(\mathrm{R}, \mathrm{R})$ as the resulting structures were most likely less rigid in comparison to $3(\mathrm{~S}, \mathrm{~S}), 4(\mathrm{R}, \mathrm{R})$. The conformational changes of these chiral ligands upon complexation with Eu(III) ions were monitored by following the 
changes in the CD spectra. Recording CPL spectra for [Eu2:L3] allowed us to assign absolute configuration of $\mathrm{Eu}(\mathrm{III})$ centres and calculate the dissymmetry factor values.

The luminescence quantum yields between [Eu2:L3] with $\mathrm{L}=4(\mathrm{R}, \mathrm{R})$ and $5(\mathrm{~S}, \mathrm{~S})$ assemblies were surprisingly similar with the highest quantum yield being observed for Eu(III) complex with 1,3-phenylenedimethanamine linker $(\mathrm{L}=1(\mathrm{~S}, \mathrm{~S}))$.

The mass-spectrometry analysis of the solid complexes shown the presence of [Eu2:L3] assemblies. However, the results revealed the presence of [Eu3:L2] and [Eu3:L3] assemblies suggesting the presence of more complicated species in the solid state at high concentration. 1H NMR titration study performed at higher concentration than spectroscopical studies confirmed the formation of highly symmetrical [Eu2:L3] helical species in solution for the systems with $\mathrm{L}=3(\mathrm{~S}, \mathrm{~S}), 4(\mathrm{R}, \mathrm{R})$ while indicating slower kinetics of the complexes formation for the ligands with bulkier spacer $L=5(S, S), 6(R, R)$.

In summary, the formation of chiral, luminescent [Eu2:L3] assemblies with high stability constants has been demon- strated in solution, while the composition of the assemblies in the solid state was more complex. The diversity of these systems allowed us to investigate their formation using various techniques and help their development towards materials for the applications in electronics for virtual reality applications (3D screens) and in medical diagnostic. We are exploring these avenues in greater details.

\section{Conflicts of interest}


There are no conflicts of interest to declare.

\section{Acknowledgements}

Authors would like to thank Dr Ann Connolly (UCD) for providing the results of elemental analysis and Science Foundation Ireland (SFI) for financial support for a PI 2013 13/IA/ 1865 grant (TG).

\section{Notes and references}

1 (a) C. Piguet and J.-C. G. Bünzli, in Handbook on the Physics and Chemistry of Rare Earths, ed. K. A. Gschneidner, J.-C. Bünzli and V. Pecharsky, Elsevier, Amsterdam, 2010, vol. 40, ch. 247, pp. 301-553; (b) S. J. Bradberry, A. J. Savyasachi, M. MartínezCalvo and T. Gunnlaugsson, Coord. Chem. Rev., 2014, 273-274, 226-241; (c) D. E. Barry, D. F. Caffrey and T. Gunnlaugsson, Chem. Soc. Rev., 2016, 45, 3244-3274; (d) C. Lincheneau, F. Stomeo, S. Comby and T. Gunnlaugsson, Aust. J. Chem., 2011, 64, 13151326; (e) J.-C. G. Bünzli, Eur. J. Inorg. Chem., 2017, 5058-5063; ( f ) J.-C. G. Bünzli, Handbook on the Physics and Chemistry of Rare Earths, ed. J.-C. G. Bünzli and V. K. Pecharsky, Elsevier, Amsterdam, 2016, vol. 50, ch. 287, pp. 141-176.

2 (a) C. Piguet, A. F. Williams and G. Bernardinelli, Angew. Chem., Int. Ed., Engl., 1992, 31, 1622-1624; (b) Y. Xing, Y. Li, L. Yan and R. Yang, Gaodeng Xuexiao Huaxue Xuebao, 1992, 13(1), 14-17.

3 (a) D. Zare, Y. Suffren, H. Nozary, A. Hauser and C. Piguet, Angew. Chem., Int. Ed., 2017, 56(46), 14612-14617; (b) T. N. Y. Hoang, Z. Wang, L. Babel, H. Nozary, M. Borkovec, I. Szilagyi and C. Piguet, Dalton Trans., 2015, 44, 13250-13260. 
4 (a) M. Cantuel, G. Bernardinelli, G. Muller, J. P. Riehl and C. Piguet, Inorg. Chem., 2004, 43, 1840-1849; (b) L. Wang, C. Xu, Q. Han, X. Tang, P. Zhou, R. Zhang, G. Gao, B. Xu, W. Qin and W. Liu, Chem. Commun., 2018, 54, 2212-2215.

5 S. N. Semenov, A. Yu. Rogachev, S. V. Eliseeva, C. Pettinari, F. Marchetti, A. A. Drozdov and S. I. Troyanov, Chem. Commun., 2008, 1992-1994.

(a) C. D. B. Vandevyver, A.-S. Chauvin, S. Comby and J.-C. G. Bünzli, Chem. Commun., 2007, 1716-1718; (b) V. Fernandez-Moreira, B. Song, V. Sivagnanam, A.-S. Chauvin, C. D. B. Vandevyver, M. Gijs, I. Hemmilä, H.-A. Lehr and J.-C. G. Bünzli, Analyst, 2010, 135, 42-52; (c) E. M. Surender, S. Comby, B. Cavanagh, O. Brennan, T. C. Lee and T. Gunnlaugsson, Chem, 2016, 1, 438-455; (d) E. M. Surender, S. Comby, S. Martyn, B. Cavanagh, T. C. Lee, D. F. Brougham and T. Gunnlaugsson, Chem. Commun., 2016, 52, 10858-10861; (e) S. Comby, E. M. Surender, O. Kotova, L. K. Truman, J. K. Molloy and T. Gunnlaugsson, Inorg. Chem., 2014, 53, 1867-1879.

7 (a) J. Shoo, R. Arunachalam, P. S. Subramanian, E. Suresh, A. Valkonen, K. Rissanen and M. Albrecht, Angew. Chem., Int. Ed., 2016, 55, 9625-9629; (b) W. Chen, X. Tang, W. Dou, B. Wang, L. Guo, Z. Ju and W. Liu, Chem. - Eur. J., 2017, 23, 9804-9811.

8 (a) F. Stomeo, C. Lincheneau, J. P. Leonard, J. E. O’Brien, R. D. Peacock, C. P. McCoy and T. Gunnlaugsson, J. Am. Chem. Soc., 2009, 131, 9636-9637; (b) C. Lincheneau, R. D. Peacock and T. Gunnlaugsson, Chem. - Asian J., 2010, 5, 500-504; (c) S. Comby, F. Stomeo, C. P. McCoy and T. Gunnlaugsson, Helv. Chim. Acta, 2009, 92, 2461-2473; (d) T. Zhang, G.-L. Zhang, L.-P. Zhou, X.-Q. Guo and Q.-F. Sun, Tetrahedron: Asymmetry, 2017, 28, 550-554; (e) C.-T. Yeung, W. T. K. Chan, S.-C. Yan, K.-L. Yu, K.-H. Yim, W.-T. Wong and G.-L. Law, Chem. Commun., 2015, 51, 592-595; ( f ) M. Albrecht, S. Schmid, S. Dehn, C. Wickleder, S. Zhang, A. P. Bassett, Z. Pikramenou and R. Fröhlich, New J. Chem., 2007, 31, 1755-1762; (g) C. Lincheneau, B. Jean-Denis and T. Gunnlaugsson, Chem. Commun., 
2014, 50, 2857-2860; (h) E. P. McCarney, J. P. Byrne, B. Twamley, M. Martinez-Calvo, G. Ryan, M. E. Möbius and T. Gunnlaugsson, Chem. Commun., 2015, 51, 14123-14126; (i) J. P. Byrne, J. A. Kitchen, J. E. O’Brien, R. D. Peacock and T. Gunnlaugsson, Inorg. Chem., 2015, 54, 1426-1439.

9 S. Zebret, E. Vögele, T. Klumpler and J. Hamacek, Chem. - Eur. J., 2015, 21, 6695-6699. 10 B. E. Aroussi, S. Zebret, C. Besnard, P. Perrottet and J. Hamacek, J. Am. Chem. Soc., 2011, 133, 10764-10710.

11 X.-Z. Li, L.-P. Zhou, L.-L. Yan, D.-Q. Yuan, C.-S. Lin and Q.-F. Sun, J. Am. Chem. Soc., $2017,139(24), 8237-8244$.

12 (a) C.-L. Liu, L.-P. Zhou, D. Tripathy and Q.-F. Sun, Chem. Commun., 2017, 53, 2459 2462; (b) L.-L. Yan, C.-H. Tan, G.-L. Zhang, L.-P. Zhou, J.-C. G. Bünzli and Q.-F. Sun, J. Am. Chem. Soc., 2015, 137, 8550-8555; (c) C.-T. Yeung, K.-H. Yim, H.-Y. Wong, R. Pal, W.-S. Lo, S.-C. Yan, M. Y.-M. Wong, D. Yufit, D. E. Smiles, L. J. McCormick, S. J. Teat, D. K. Shuh, W.-T. Wong and G.-L. Law, Nat. Commun., 2017, 8, 1128.

13 (a) A. P. Bassett, S. W. Magennis, P. B. Glover, D. J. Lewis, N. Spencer, S. Parsons, R. M. Williams, L. De Cola and Z. Picramenou, J. Am. Chem. Soc., 2004, 126, 9413-9424; (b) J. Shi, Y. Hou, W. Chu, X. Shi, H. Gu, B. Wang and Z. Sun, Inorg. Chem., 2013, 52, 50135022.

14 T. Y. Bing, T. Kawai and J. Yuasa, J. Am. Chem. Soc., 2018, 140, 3683-3689.

15 (a) J.-F. Ayme, G. Gil-Ramírez, D. A. Leigh, J.-F. Lemonnier, A. Markevicius, C. A. Muryn and G. Zhang, J. Am. Chem. Soc., 2014, 136, 13142-13145; (b) G. Zhang, G. GilRamírez, A. Markevicius, C. Browne, I. J. Vitorica-Yrezabal and D. A. Leigh, J. Am. Chem. Soc., 2015, 137, 10437-10442; (c) G. Gil-Ramírez, S. Hoekman, M. O. Kitching, D. A. Leigh, I. J. Vitorica-Yrezabal and G. Zhang, J. Am. Chem. Soc., 2016, 138, 13159-13162; (d) L. Zhang, D. P. August, J. Zhong, G. F. S. Whitehead, I. J. Vitorica- Yrezabal and D. A. 
Leigh, J. Am. Chem. Soc., 2018, 140, 4982-4985; (e) D. A. Leigh, L. Pirvu, F.

Schaufelberger, D. J. Tetlow and L. Zhang, Angew. Chem., Int. Ed., 2018, 57, 10484-10488.

16 J. R. Lakowicz, Principles of Fluorescence Spectroscopy, Springer, 3rd edn, 2006, p. 954.

17 (a) C. Hunter, J. Chem. Soc., Chem. Commun., 1991, 749- 751; (b) C. Hunter, J. Am.

Chem. Soc., 1992, 114, 5303-5311. 18 (a) K. Binnemans and C. Görller-Warland, J. Rare

Earths, 1996, 14, 173-180; (b) K. Binnemans, Coord. Chem. Rev.,

$2015,295,1-45$.

19 (a) J. P. Leonard, P. Jensen, T. McCabe, J. E. O_Brien, R. D. Peacock, P. E. Kruger and T. Gunnlaugsson, J. Am. Chem. Soc., 2007, 129, 10986-10987; (b) O. Kotova, J. A. Kitchen, C. Lincheneau, R. D. Peacock and T. Gunnlaugsson, Chem. - Eur. J., 2013, 19, 16181-16186.

20 (a) H. Gampp, M. Maeder, C. J. Meyer and A. D. Zuberbühler, Talanta, 1986, 33, 943-

951; (b) H. Gampp, M. Maeder, C. J. Meyer and A. D. Zuberbühler, Talanta, 1985, 23, $1133-$ 1139.

21 (a) R. V. Person, K. Monde, H.-U. Humpf, N. Berova and K. Nakanishi, Chirality, 1995, 7, 128-135; (b) G. A. Hembury, V. V. Borovkov and Y. Inoue, Chem. Rev., 2008, 108, 1-73; (c) N. Berova, L. Di Bari and G. Pescitelli, Chem. Soc. Rev., 2007, 36, 914-931.

22 (a) O. Kotova, S. Blasco, B. Twamley, J. O’Brien, R. D. Peacock, J. A. Kitchen, M. Martínez-Calvo and T. Gunnlaugsson, Chem. Sci., 2015, 6, 457-471; (b) A. Galanti, O. Kotova, S. Blasco, C. J. Johnson, R. D. Peacock, S. Mills, J. J. Boland, M. Albrecht and T. Gunnlaugsson, Chem. - Eur. J., 2016, 22, 9709-9723; (c) J. P. Byrne, M. Martínez-Calvo, R. D. Peacock and T. Gunnlaugsson, Chem. - Eur. J., 2016, 22, 486-490; (d) S. J. Bradberry, A. J. Savyasachi, R. D. Peacock and T. Gunnlaugsson, Faraday Discuss., 2015, 185, 413-431; (e) J. P. Byrne, J. A. Kitchen and T. Gunnlaugsson, Chem. Soc. Rev., 2014, 43, 5302-5325. 23 (a) N. Fatin-Rouge, S. Blanc, A. Pfeil, A. Rigault, A.-M. Albrecht-Gary and J.-M. Lehn, Helv. Chim. Acta, 2001, 84, 1694-1711; (b) C. A. Hunter and H. L. Anderson, Angew. 
Chem., Int. Ed., 2009, 48, 7488-7499; (c) G. Ercolani and L. Schiaffino, Angew. Chem., Int. Ed., 2011, 50, 1762-1768; (d) J. Hamacek, S. Blanc, M. Elhabiri, E. Leize, A. Van Dorsselaer, C. Piguet and A.-M. Albrecht-Gary, J. Am. Chem. Soc., 2003, 125, 1541-1550. 24 M. H. V. Werts, R. T. F. Jukes and J. W. Verhoven, Phys. Chem. Chem. Phys., 2002, 4, $1542-1548$.

25 J.-C. G. Bünzli and S. V. Eliseeva, in Lanthanide Luminescence: Photophysical, Analytical and Biological Aspects, ed. P. Hänninen and H. Härmä, Springer Ser. Fluoresc., 2010, pp. $1-46$.

26 (a) A. V. Davis, R. M. Yeh and K. N. Raymond, Proc. Natl. Acad. Sci. U. S. A., 2002, 8, 4793-4796; (b) G. Ercolani and L. Schiaffino, Angew. Chem., Int. Ed., 2011, 50, $1762-$ 1768.

27 Analytical Methods in Supramolecular Chemistry, ed. C. A. Schalley, 2007, p. 484. 